\title{
Endoplasmic Reticulum Targeting and Insertion of Tail-Anchored Membrane Proteins by the GET Pathway
}

\author{
Vladimir Denic ${ }^{1}$, Volker Dötsch², and Irmgard Sinning ${ }^{3}$ \\ ${ }^{1}$ Department of Molecular and Cellular Biology, Harvard University, Northwest Laboratories, Cambridge, \\ Massachusetts 02138 \\ ${ }^{2}$ Institute for Biophysical Chemistry, Centre for Biomolecular Magnetic Resonance, Goethe University, \\ D-60325 Frankfurt am Main, Germany \\ ${ }^{3}$ Heidelberg University Biochemistry Center (BZH), D-69120 Heidelberg, Germany \\ Correspondence: vdenic@mcb.harvard.edu; vdoetsch@em.unifrankfurt.de; irmi.sinning@bzh.uni-heidelberg.de
}

Hundreds of eukaryotic membrane proteins are anchored to membranes by a single transmembrane domain at their carboxyl terminus. Many of these tail-anchored (TA) proteins are posttranslationally targeted to the endoplasmic reticulum (ER) membrane for insertion by the guided-entry of TA protein insertion (GET) pathway. In recent years, most of the components of this conserved pathway have been biochemically and structurally characterized. Get3 is the pathway-targeting factor that uses nucleotide-linked conformational changes to mediate the delivery of TA proteins between the GET pretargeting machinery in the cytosol and the transmembrane pathway components in the ER. Here we focus on the mechanism of the yeast GET pathway and make a speculative analogy between its membrane insertion step and the ATPase-driven cycle of $\mathrm{ABC}$ transporters.

$T^{\mathrm{h}}$ he mechanism of membrane protein insertion into the endoplasmic reticulum (ER) has been extensively studied for many years (Shao and Hegde 2011). From this work, the signal recognition particle (SRP)/Sec61 pathway has emerged as a textbook example of a cotranslational membrane insertion mechanism (Grudnik et al. 2009). The SRP binds a hydrophobic segment (either a cleavable amino-terminal signal sequence or a transmembrane domain) immediately after it emerges from the ribosomal exit tunnel. This results in a translational pause that persists until SRP engages its receptor in the ER and delivers the ribosomenascent chain complex to the Sec61 channel. Last, the Sec61 channel enables protein translocation into the ER lumen along with partitioning of hydrophobic transmembrane domains into the lipid bilayer through the Sec61 lateral gate (Rapoport 2007).

Approximately $5 \%$ of all eukaryotic membrane proteins have an ER targeting signal in a single carboxy-terminal transmembrane domain that emerges from the ribosome exit tunnel following completion of protein synthesis and is not recognized by the SRP (Stefanovic

Editors: Susan Ferro-Novick, Tom A. Rapoport, and Randy Schekman

Additional Perspectives on The Endoplasmic Reticulum available at www.cshperspectives.org

Copyright (C) 2013 Cold Spring Harbor Laboratory Press; all rights reserved; doi: 10.1101/cshperspect.a013334

Cite this article as Cold Spring Harb Perspect Biol 2013;5:a013334 
V. Denic et al.

and Hegde 2007). Nonetheless, because hydrophobic peptides in the cytoplasm are prone to aggregation and subject to degradation by quality control systems (Hessa et al. 2011), these tailanchored (TA) proteins still have to be specifically recognized, shielded from the aqueous environment, and guided to the ER membrane for insertion. In the past five years, the guidedentry of TA proteins (GET) pathway has come to prominence as the major machinery for performing these tasks and the enabler of many key cellular processes mediated by TA proteins including vesicle fusion, membrane protein insertion, and apoptosis. This research has rapidly yielded biochemical and structural insights (Tables 1 and 2) into many of the GET pathway components (Hegde and Keenan 2011; Chartron et al. 2012a; Denic 2012). In particular, Get3 is an ATPase that uses metabolic energy to bridge recognition of TA proteins by upstream pathway components with TA protein recruitment to the ER for membrane insertion. However, the precise mechanisms of nucleotide-dependent TA protein binding to Get3 and how the GET pathway inserts tail anchors into the membrane are still poorly understood. Here, we provide an overview of the budding yeast GET pathway with emphasis on mechanistic insights that have come from structural studies of its membrane-associated steps and make a speculative juxtaposition with the $\mathrm{ABC}$ transporter mechanism.

\section{TA PROTEIN CAPTURE BY THE GET PATHWAY}

The first step in all membrane protein insertion pathways is the selective capture of substrates. The carboxy-terminal hydrophobic anchors of TA proteins do not interact efficiently with SRP after they emerge from the ribosome exit tunnel following completion of protein synthesis (Stefanovic and Hegde 2007). Instead, they are shielded from the aqueous environment by the pretargeting complex of the GET pathway, which comprises Sgt2 (a small glutamine-rich tetratricopeptide repeat $[\mathrm{TPR}]$-containing protein), Get4, and Get5 (Fig. 1). Sgt2 binds directly to tail anchors via its carboxy-terminal
Table 1. A catalog of GET pathway component structures

\begin{tabular}{|c|c|c|}
\hline Component & Role in the pathway & PDB ID \\
\hline Sgt2 & $\begin{array}{l}\text { Component of the } \\
\text { pretargeting complex } \\
\text { that delivers TA } \\
\text { proteins to Get3; dimer } \\
\text { interacts with Get4/ } \\
\text { Get5, contains TPR } \\
\text { repeats that interact } \\
\text { with Hsps }\end{array}$ & $3 S Z 7$ \\
\hline Get5 & $\begin{array}{l}\text { Component of the } \\
\text { pretargeting complex } \\
\text { that delivers TA } \\
\text { proteins to Get3; dimer } \\
\text { interacts with Get } 4 \text { via } \\
\text { amino-terminal } \\
\text { domain and with Sgt2 } \\
\text { via its ubiquitin-like } \\
\text { domain }\end{array}$ & $\begin{array}{l}\text { 2LNZ } \\
\text { 3VEJ } \\
2 \mathrm{LO} 0\end{array}$ \\
\hline Get4 & $\begin{array}{l}\text { Component of the } \\
\text { pretargeting complex } \\
\text { that delivers TA } \\
\text { proteins to Get3; } \\
\text { interacts with Get3 via } \\
\text { amino-terminal } \\
\text { domain and with Get4 } \\
\text { via carboxy-terminal } \\
\text { domain }\end{array}$ & $\begin{array}{l}\text { 3LPZ } \\
\text { 3LKU } \\
\text { 3WPV }\end{array}$ \\
\hline Get3 & $\begin{array}{l}\text { ATPase that binds the TA } \\
\text { protein; dimer interacts } \\
\text { with the pretargeting } \\
\text { complex in the cytosol, } \\
\text { and with Get } 1 / 2 \text { at the } \\
\text { ER membrane }\end{array}$ & Table 2 \\
\hline Get1 & $\begin{array}{l}\text { ER receptor for Get3; } \\
\text { integral ER membrane } \\
\text { protein, three TMDs; } \\
\text { forms a complex with } \\
\text { Get2 }\end{array}$ & $\begin{array}{l}\text { 3SJA, 3SJB } \\
\text { 3SJC, } \\
\text { 3ZS8 } \\
\text { 3VLC, } \\
\text { 3B2E }\end{array}$ \\
\hline Get2 & $\begin{array}{l}\text { ER receptor for Get3; } \\
\text { integral ER membrane } \\
\text { protein, three TMDs; } \\
\text { forms a complex with } \\
\text { Get } 1\end{array}$ & $\begin{array}{l}\text { 3SJD } \\
\text { 3ZS9 }\end{array}$ \\
\hline
\end{tabular}

TA, tail anchored; TPR, tetratricopeptide repeat; TMDs, transmembrane domains.

domain, which is able to discriminate between TA proteins destined for the ER and those destined for the mitochondria (Wang et al. 2010). Defining the structural basis of substrate 
Table 2. An itemized list of published Get3 structures with associated nucleotides and conformation nomenclature

\begin{tabular}{|c|c|c|c|c|}
\hline Organism & Nucleotide & Conformation & PDB ID & References \\
\hline \multicolumn{5}{|l|}{ Get3 } \\
\hline Schizosaccharomyces pombe & None & Open & 2WOO & Mateja et al. 2009 \\
\hline \multirow[t]{2}{*}{ Saccharomyces cerevisiae } & None & Open & $3 \mathrm{H} 84$ & Hu et al. 2009 \\
\hline & & & $3 \mathrm{~A} 36$ & Yamagata et al. 2010 \\
\hline Aspergillus fumigatus & ADP & Open & 3IBG & Suloway et al. 2009 \\
\hline S. cerevisiae & ADP & Open & $3 \mathrm{~A} 37$ & Yamagata et al. 2010 \\
\hline Debaryomyces hansenii & $\mathrm{ADP}$ & Closed & $3 \mathrm{IO} 3$ & Hu et al. 2009 \\
\hline Chaetomium thermophilum & AMPPNP-Mg ${ }^{2+}$ & Closed & 3IQW & Bozkurt et al. 2009 \\
\hline C. thermophilum & $\mathrm{ADP}-\mathrm{Mg}^{2+}$ & Closed & $3 I Q X$ & Bozkurt et al. 2009 \\
\hline S. cerevisiae & $\mathrm{ADP} \cdot \mathrm{AlF}_{4}^{-}-\mathrm{Mg}^{2+}$ & Fully closed & $2 \mathrm{WOJ}$ & Mateja et al. 2009 \\
\hline $\begin{array}{l}\text { Methanothermobacter } \\
\text { thermautotrophicus }\end{array}$ & $\mathrm{ADP} \cdot \mathrm{AlF}_{4}^{-}-\mathrm{Mg}^{2+}$ & Fully closed & 3ZQ6 & Sherill et al. 2011 \\
\hline \multirow[t]{2}{*}{ Methanococcus jannaschii } & $\mathrm{ADP} \cdot \mathrm{AlF}_{4}^{-}-\mathrm{Mg}^{2+}$ & Tetrameric & 3UG6 & Suloway et al. 2012 \\
\hline & & & 3UG7 & \\
\hline \multicolumn{5}{|l|}{ Get3/Get $2_{\text {cyto }}$} \\
\hline S. cerevisiae & $\mathrm{ADP}-\mathrm{Mg}^{2+}$ & Closed & 3SJD & Stefer et al. 2011 \\
\hline S. cerevisiae & $\mathrm{ADP} \cdot \mathrm{AlF}_{4}^{-}-\mathrm{Mg}^{2+}$ & Closed & $3 Z S 9$ & Mariappan et al. 2011 \\
\hline \multicolumn{5}{|l|}{ Get3/Get $1_{\text {cyto }}$} \\
\hline S. cerevisiae & None & Semiopen & 3SJC & Stefer et al. 2011 \\
\hline S. cerevisiae & $\mathrm{ADP}$ & Semiopen & $3 \mathrm{VLC}$ & Kubota et al. 2012 \\
\hline \multirow[t]{4}{*}{ S. cerevisiae } & None & Open & 3SJA & Stefer et al. 2011 \\
\hline & & & $3 S J B$ & Stefer et al. 2011 \\
\hline & & & 3ZS8 & Mariappan et al. 2011 \\
\hline & ADP & Open & $3 \mathrm{~B} 2 \mathrm{E}$ & Kubota et al. 2012 \\
\hline
\end{tabular}

ADP, adenosine diphosphate.

recognition by this Sgt 2 domain has been hampered by its poorly folded nature (Chartron et al. 2011) but we have more structural information on the other Sgt2 domains and components of the pretargeting complex. The central TPR domain of Sgt2 has a canonical structure that enables it to associate with a variety of chaperones (Wang et al. 2010; Chartron et al. 2011; Kohl et al. 2011). Sgt2's amino-terminal domain mediates both homodimerization and binding to the central, ubiquitin-like domain of Get5 (Liou and Wang 2005; Chang et al. 2010; Chartron et al. 2011). The carboxy-terminal domain of Get5 assumes a novel, helical bundle fold that mediates homodimerization (Chartron et al. 2012b). Get4 is an elongated, $\alpha$-helical solenoid (Bozkurt et al. 2010; Chang et al. 2010; Chartron et al. 2010) that forms a tight complex with the amino terminus of Get5 at one end and a more labile complex with Get3 at the other (Chang et al. 2010; Chartron et al.
2010). In addition to this wealth of piecemeal structural information, a key insight into the function of Get4/5 came from the observation that these components of the GET pathway facilitate transfer of TA proteins from Sgt2 to Get3 by a dual mechanism (Wang et al. 2010). They increase the local concentration of Get 3 near TA proteins held by Sgt 2 and make Get 3 more receptive for substrate binding. The precise stoichiometry and mechanistic details of the pretargeting step in the GET pathway remain to be worked out. For example, do Get4/5 enable a TA protein "hand-off" mechanism between Sgt2 and Get3 during which the substrate's hydrophobic anchor is transiently bound to both TA protein chaperones? What mechanism makes Get3 more receptive to bind TA proteins when it becomes transiently recruited to the pretargeting complex? Regardless of these details, the baroque nature of the pretargeting step in the GET pathway suggests that this 
V. Denic et al.

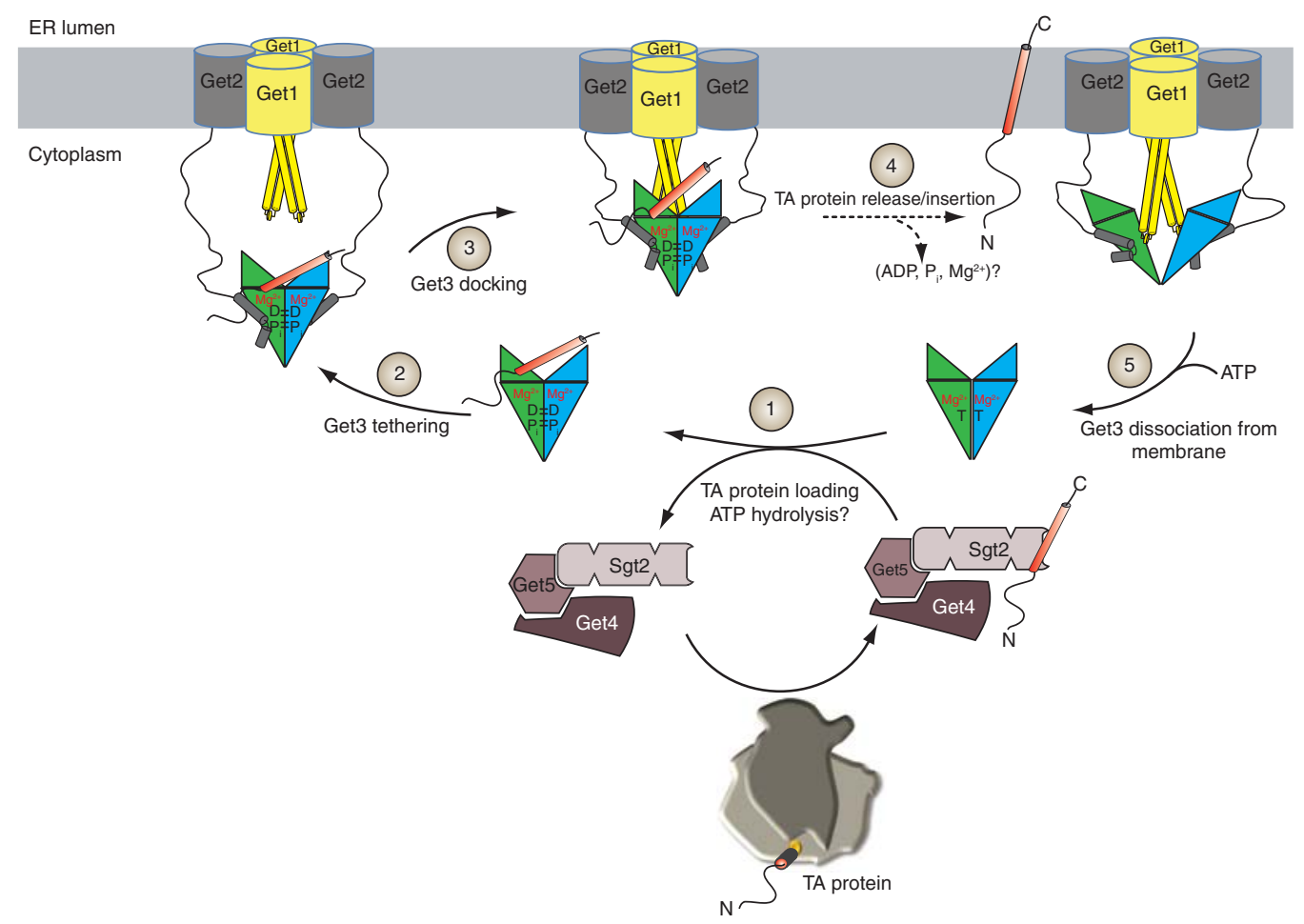

Figure 1. Scheme of the steps in the yeast GET pathway. The cytosolic pretargeting complex (Get4/Get5/Sgt2) captures a newly synthesized tail-anchored (TA) protein released from the ribosome (with differentially shaded large and small subunits) and transfers it to Get3 loaded with ATP (1). The Get3-TA protein complex is subsequently tethered to the endoplasmic reticulum (ER) membrane by the cytosolic domain of Get2 (2) and then docked to the Get1 coiled coil (3). This latter interaction drives TA protein release by forcing open the Get3 dimer (4). Finally, rebinding of ATP dissociates Get3 from the membrane and prepares it for the next round of substrate pretargeting (5). The precise timing of ATP hydrolysis is not known but we have several reasons to favor a model in which it occurs on TA protein binding to Get3. First, the crystal structures of Get3 that have an assembled substrate-binding groove also have an ATP hydrolysis transition-state analog. Second, Get3 ATPase activity is essential for the TA protein release step. Third, the Get 1 coiled coil preferentially binds to the apo form of Get3. Also note that for simplicity the higher-order stoichiometry of the pretargeting complex is not shown, whereas the stoichiometry of the Get1/2 transmembrane complex is hypothetically drawn as a 2:2 tetramer.

mechanism is being used to rapidly and selectively channel the appropriate substrates from the ribosome to Get3.

\section{TA PROTEIN RECOGNITION BY THE Get3 ATPase}

Get3 is an ATPase of the SIMIBI class of nucleotide triphosphate (NTP)-binding proteins (Leipe et al. 2002). The function of Get3 is to shuttle TA proteins between the pretargeting complex in the cytoplasm and the transmem- brane components of the GET pathway in the ER (Schuldiner et al. 2008). Numerous crystal structures of fungal Get3 proteins in different nucleotide-bound states have yielded a plausible structural model for substrate recognition by Get3 (Simpson et al. 2010). Specifically, Get3 is a homodimer with subunit interactions stabilized by a coordinated zinc ion. Each monomer comprises a core nucleotide-binding domain (NBD) with interspersed $\alpha$-helical insertions. Several pieces of evidence argue that these helices comprise the TA protein-binding domain 
(TABD). First, the TABD helices are amphipathic and enriched in methionine and hydrophobic residues, a structural feature shared with the $M$ domain of the SRP, which is involved in signal sequence binding (Keenan et al. 1998; Rosendal et al. 2003; Janda et al. 2010; Hainzl et al. 2011). Moreover, hydrophilic mutations at these residues result in reduced TA protein binding to Get3 (Mateja et al. 2009). Second, in certain nucleotide-bound states (see below), the TABD becomes structured into a large, composite hydrophobic groove with contributions from both monomers and the appropriate dimensions to receive an $\alpha$-helical tail anchor (Mateja et al. 2009). Last, hydrogen-deuterium exchange mass spectrometry experiments have revealed that specific parts of the TABD are protected from exchange by TA protein binding (Bozkurt et al. 2009).

Although the TABD is undoubtedly the site of TA protein binding to Get3, the precise stoichiometry of Get3-TA protein complexes is a matter of debate. Small-angle X-ray scattering and analytical ultracentrifugation studies with fungal Get3 homologs have found that Get3 bound to TA proteins is a tetramer (Bozkurt et al. 2009; Suloway et al. 2012). This view is further supported by the crystal structure of an archaeal Get3 homolog showing a tetramer with a head-to-head arrangement of TABDs (Suloway et al. 2012). It is worth pointing out that tetrameric Get3 species bound to TA proteins come from proteins co-overexpressed in $E s$ cherichia coli in the absence of the pretargeting pathway components. Future studies should establish the stoichiometry of Get3-TA protein complexes assembled following TA protein delivery by Get4/Get5/Sgt2 (Wang et al. 2010).

The crystal structures of the Get 3 dimer have also revealed how nucleotide-dependent conformational changes in the NBD are propagated to the TABD (Fig. 2). Specifically, in the apo and $\mathrm{Mg}^{2+}$-free ADP states, the Get3 dimer is "open," whereas ADP. $\mathrm{Mg}^{2+}$ and AMPPNP. $\mathrm{Mg}^{2+}$ induce a "closed" conformation. Furthermore, in the transition state of ATP hydrolysis (mimicked by $\mathrm{ADP}^{-} \mathrm{AlF}_{4}^{-} \cdot \mathrm{Mg}^{2+}$ ), Get3 assumes a "fully closed" state in which the hydrophobic groove of the TABD is assembled. A recent free energy calculation study of the Get3 opening and closing pathway (Wereszczynski and McCammon 2012) corroborates these findings and, in addition, postulates that Get3 can adopt a "wide open" apo state, as well as a "semiopen," asymmetric nucleotide conformation with one ADP and one ATP. This latter conformation might be reminiscent of the one observed in a crystal structure of Get3 complexed with a piece of its ER receptor (see below). In sum, these experimental and computational studies have revealed a plausible mechanistic framework for how the Get3 nucleotide-linked conformational changes coordinate the pretargeting and membrane-associated steps of the GET pathway.

\section{MEMBRANE RECRUITMENT OF Get3-TA PROTEIN COMPLEXES}

Following the pretargeting events in the GET pathway, Get3-TA protein complexes are recruited to the ER membrane by Get1 and Get2 (Fig. 1, steps 2 and 3) (Schuldiner et al. 2008). These two membrane proteins each have three transmembrane domains that mediate formation of a stable transmembrane complex (Mariappan et al. 2011). The intimate nature of this association is well illustrated by the observation that deletion of either Get1 or Get2 leads to a significant reduction in the concentration of the partner protein (Schuldiner et al. 2008; Mariappan et al. 2011; Wang et al. 2011). Two recent structural studies argue that the aminoterminal cytoplasmic domain of Get2 mediates the initial contact between the Get3-TA protein complex and Get1/2 (Mariappan et al. 2011; Stefer et al. 2011). Specifically, even though the isolated cytoplasmic domain of Get2 $(\sim 140$ amino acids) is for the most part unstructured, it can form a 2:2 complex with Get3. Crystal structures of this complex have revealed a pair of short Get2 helices ( $\alpha 1$ and $\alpha 2)$ that interact with Get3. Importantly, the Get3 dimer can interact with Get2 in a closed, nucleotide-bound state that is compatible with TA protein binding. This is because the Get2 binding site on Get3 is a monomeric epitope located away from the homodimerization interface. Binding is for the most part mediated by electrostatic 
V. Denic et al.
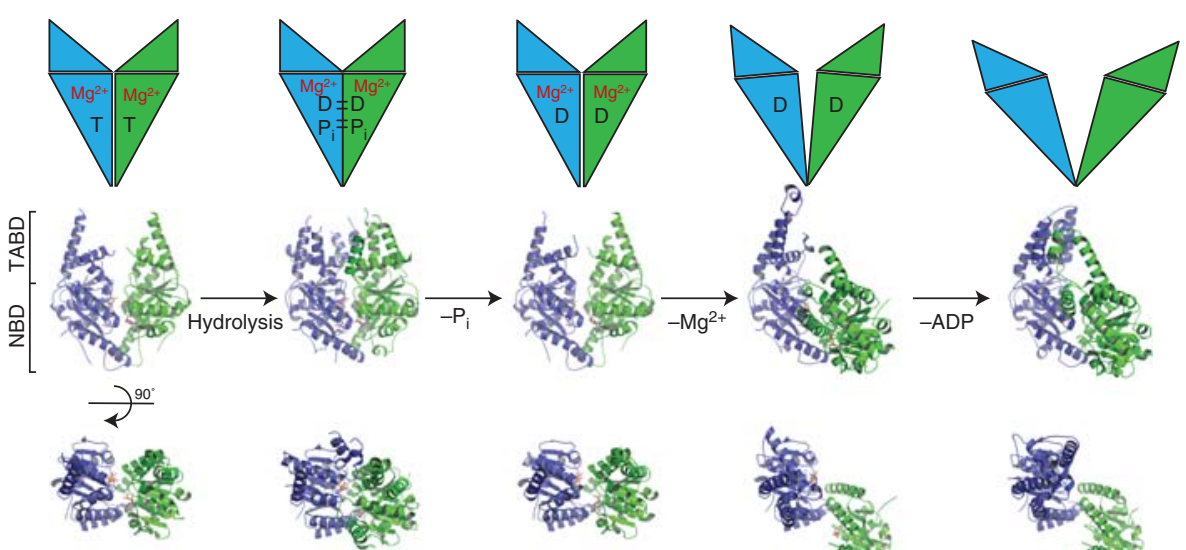

Nucleotide state: AMPPNP-Mg²+
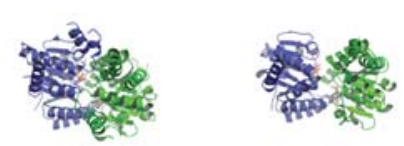

Get3 conformation: Closed
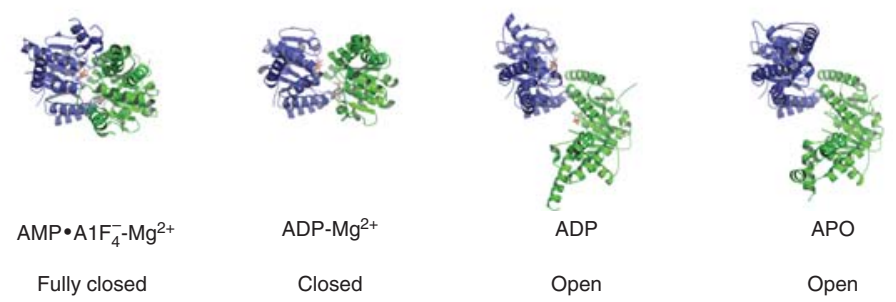

Figure 2. Get3 conformations during its ATPase cycle. Get3 is a homodimeric ATPase (monomers are in blue and green) that comprises an $\alpha$-helical TA protein-binding domain (TABD) and a nucleotide-binding domain (NBD). The upper panels show cartoon representations of the Get3 dimer, whereas the middle and lower panels show the corresponding crystal structures from the side or top, respectively (see Table 2 for the PDB entry codes). These structures are presented as a sequence of conformational changes that might accompany the Get 3 ATPase cycle. Get3 bound to ATP most likely resembles the closed dimer conformation stabilized by AMPPNP-Mg ${ }^{2+}(\mathrm{a}$ nonhydrolyzable ATP analog). In the process of ATP hydrolysis, a state stabilized by the ATP transition-state analog $\mathrm{ADP} \cdot \mathrm{AlF}_{4}^{-}-\mathrm{Mg}^{2+}$, Get3 assumes a full-closed conformation that leads to the assembly of a composite, hydrophobic groove in the TABD. Following release of inorganic phosphate $\left(\mathrm{P}_{\mathrm{i}}\right)$, Get3 reverts to a more relaxed closed state similar to the one preceding hydrolysis. Last, in the absence of $\mathrm{Mg}^{2+}$, Get3-ADP assumes an open conformation, which also resembles the nucleotide-free (apo) state. All Get3 structures have been superimposed by the blue monomer to illustrate that nucleotide-driven dimer opening and closing is not simply a scissor-like motion, but involves substantial rotation of the monomers.

interactions between the conserved RERR sequence on the Get $2 \alpha 1$ helix and the negatively charged surface patch on Get3's NBD that includes the conserved DELYED motif. Importantly, point mutations in the RERR sequence abolish Get3/Get2 complex formation and TA protein insertion into ER-derived membranes (microsomes).

\section{TA PROTEIN RELEASE FROM Get3}

Like Get2, Get1 has a large cytoplasmic domain $(\sim 80$ amino acids) that in isolation forms a stable 2:2 complex with Get3 (Mariappan et al. 2011; Stefer et al. 2011). Structural studies of this complex support the idea that Get1 induces TA protein release from Get3 (Fig. 1, steps 3 and 4) (Mariappan et al. 2011; Stefer et al.
2011; Kubota et al. 2012). In particular, the cytoplasmic domain of Get1 is a coiled coil of two $\alpha$ helices ( $\alpha 1 b$ and $\alpha 2)$ stabilized by hydrophobic contacts similar to leucine zippers. In striking contrast to the Get3/Get2 complex, Get3 is bound to the coiled coils in an open conformation that lacks nucleotide (or has ADP; see Fig. 2) and has a disrupted TABD. This is because each coiled coil binds to both Get3 monomers via a composite epitope that is largely occluded in the closed Get3 conformation. Few interactions occur between Get1 $\alpha 1 \mathrm{~b}$ and the TABD helix $\alpha 4$ on one Get 3 monomer, but more extensive contact is established by interactions between Get $1 \alpha 2$ and NBD helices $\alpha 10$ and $\alpha 11$, which include the Get3 DELYED motif recognized by Get2, on the opposing monomer. Notably, Get1 mutations that disrupt interactions 
with the DELYED motif abolish Get3/Get1 complex formation and TA protein insertion into microsomes. The overlap between the primary Get3/Get1 interface and the Get2 binding site implied that Get1 and Get2 compete for binding to Get3. This hypothesis was confirmed by an NMR analysis showing that Get1 can displace the Get $2 \alpha 2$ helix from its binding site on Get3 while still allowing the Get $2 \alpha 1$ helix to remain bound in the ternary complex (Stefer et al. 2011). Attempts to crystallize this ternary complex revealed instead the structure of a new Get3/Get1 complex with a novel Get3 conformation: a semiopen state with respect to the closed AMPPNP- $\mathrm{Mg}^{2+}$ and ADP- $\mathrm{Mg}^{2+}$ bound structures and the open apo form (Fig. 2) (Stefer et al. 2011). Interestingly, the semiopen and open Get3 makes similar contacts with the Get2 $\alpha 2$ helix. Taken together with a related semiopen Get3/Get1 structure (Kubota et al. 2012), these studies suggest that the Get $1 \alpha 2$ helix initiates TA protein release from Get3 tethered to Get2.

The structural model for the membrane-associated steps of the GET pathway is supported by biochemical reconstitution studies (Mariappan et al. 2011; Wang et al. 2011). In particular, TA proteins remain bound to Get3 on Get2 binding, but Get1 binding triggers substrate release from Get3. Importantly, even though high concentrations of the Get 1 coiled coil can drive substrate release, under physiological conditions, the Get2 cytoplasmic domain is essential to increase the local concentration of Get3-TA protein complexes near Get1. Moreover, quantitative measurements of Get3 binding to Get1 have shown that in the ATP-bound state Get3 does not interact with Get1, whereas the apo form binds Get1 with high affinity (Mariappan et al. 2011; Stefer et al. 2011; Kubota et al. 2012). Indeed, in the crystal structures of the Get3Get1 complex, the tip helix of the Get1 coiled coil protrudes into the nucleotide-binding site of Get3 suggesting that Get1 is a nucleotide exchange factor for Get3. Regardless of the details, ATP binding drives dissociation of Get3 from the membrane (Fig. 1, step 5) and prepares it for another round of substrate loading by the pretargeting complex.

\section{THE INSERTION STEP OF THE GET PATHWAY: A SPECULATIVE ANALOGY TO ABC TRANSPORTERS}

The membrane insertion step remains the least well-understood step in the GET pathway. Proteoliposomes with purified Get1/2 afford the minimal membrane machinery necessary for TA protein insertion (Mariappan et al. 2011; Wang et al. 2011), but whether the transmembrane domains of Get1 and Get2 play an active role during this step is not known. A variety of mechanisms for Get1/2-mediated tail-anchor insertion have been hypothesized (Hegde and Keenan 2011; Chartron et al. 2012a; Denic 2012) and we add to this a speculative analogy to the substrate transport mechanism of ATPbinding cassette (ABC) transporters (Fig. 3). $\mathrm{ABC}$ transporters couple the energy of ATP hydrolysis to the transport of diverse substrates across the membrane. In general, they consist of two sets of TMDs and two NBDs that bind and hydrolyze ATP. Most ABC transporter NBDs are monomers in the absence of their TMDs but become dimerized in the presence of nonhydrolyzable ATP analogs. At first glance, the mechanistic requirements of $\mathrm{ABC}$ transporters and Get1/2/3 membrane machinery might seem disparate. However, closer inspection reveals a striking commonality. ATP binding drives rotation of both types of NBDs toward each other to create an extensive dimer interface. In $\mathrm{ABC}$ transporters, changes in the NBD conformation induced by binding and hydrolysis of ATP are transmitted to the neighboring TMDs via coupling helices. The resulting flipping of TMDs from an inward to an outward facing conformation drives substrate movement across the membrane. For TA protein insertion one could envisage a similar scenario whereby Get 1 coiled coils act as coupling helices that translate movements associated with Get3 dimer opening into conformational changes in the flanking transmembrane domains (Fig. 4). Future structural and functional analysis of the Get1/2 transmembrane complex should establish if its transmembrane domains carry out the insertion step of the GET pathway. 
V. Denic et al.

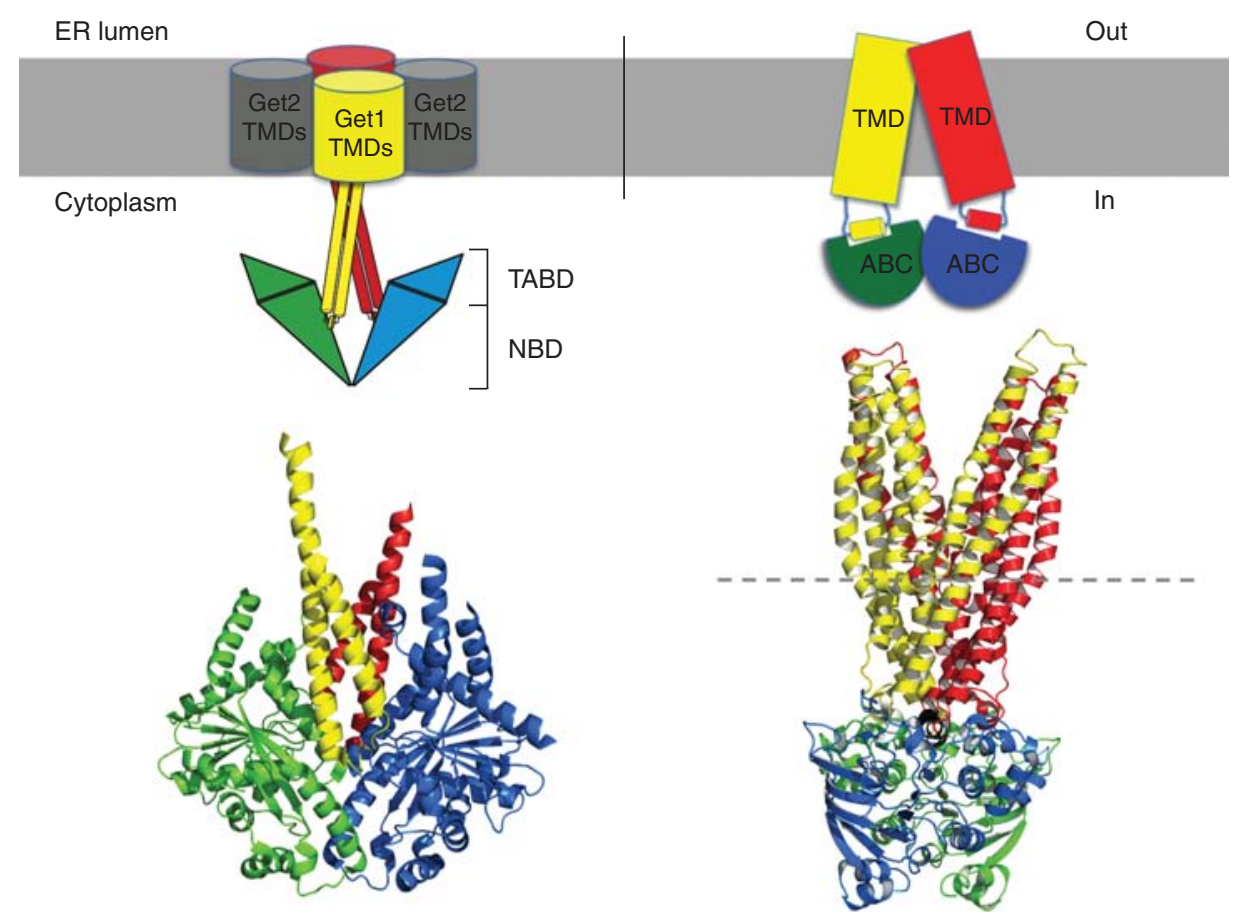

Figure 3. ABC transporters and Get1/3 interactions: A structural comparison. The upper left panel is a cartoon of a hypothetical 2:2 Get1/2 tetrameric transmembrane complex (Get1 subunits are in yellow and red; Get2 cytoplasmic domains are eliminated for simplicity) bound to a Get3 dimer (monomers are in blue and green; nucleotide and tail-anchor binding domains, NBD and TABD, respectively, are indicated) via the cytosolic coiled-coil domains of Get1. Both Get1 and Get2 are predicted to have three transmembrane domains (TMDs) each. The upper right panel is a cartoon of a generic $\mathrm{ABC}$ transporter with TMDs (ranging in number from 10 to $20)$ coupled to nucleotide-binding domains (ABC) by special $\alpha$ helices (cylinders). The lower panels are crystal structures of Get 1 coiled coils complexed with Get3 and the multidrug ABC transporter Sav1866 (Dawson and Locher 2007) (the dashed line indicates the cytosolic border of the membrane) with structural elements color coded to suggest similarities between the two structures. Note that Sav1866 is a dimer with domain-swapped interactions between the coupling helices and nucleotide-binding domains. Furthermore, the ABC domains are in a closed conformation, whereas the Get3 dimer is open (see Fig. 4 for further details).

\section{A WORKING MODEL FOR THE GET PATHWAY}

In summary, in a relatively short period of time, a detailed mechanistic framework for the GET pathway has emerged (Fig. 1). ATP $\cdot \mathrm{Mg}^{2+}$ bound Get3 receives a newly synthesized TA protein from the Get4/Get5/Sgt2 pretargeting complex. ATP hydrolysis, which probably occurs on substrate binding to Get3, ensures the formation of a stable, closed Get3-TA protein complex containing the hydrolyzed nucleotide (step 1). This complex is recruited to the ER membrane by the interaction with Get2, which tethers it into proximity with Get1 (step 2). Binding of Get1 to Get3 displaces Get2 and induces Get3 dimer opening to release the TA protein substrate and hydrolyzed nucleotide (steps 3 and 4). These changes in the Get3 dimer conformation might be directly coupled to the Get1/2 transmembrane domains to facilitate the membrane insertion step. Last, binding of ATP to Get3 weakens the Get3-Get1 interaction to recycle Get3 for a new round of pretargeting (step 5).

Arguably, the most challenging problem that remains in the field is to define the structural and biochemical basis of the insertion step. For 


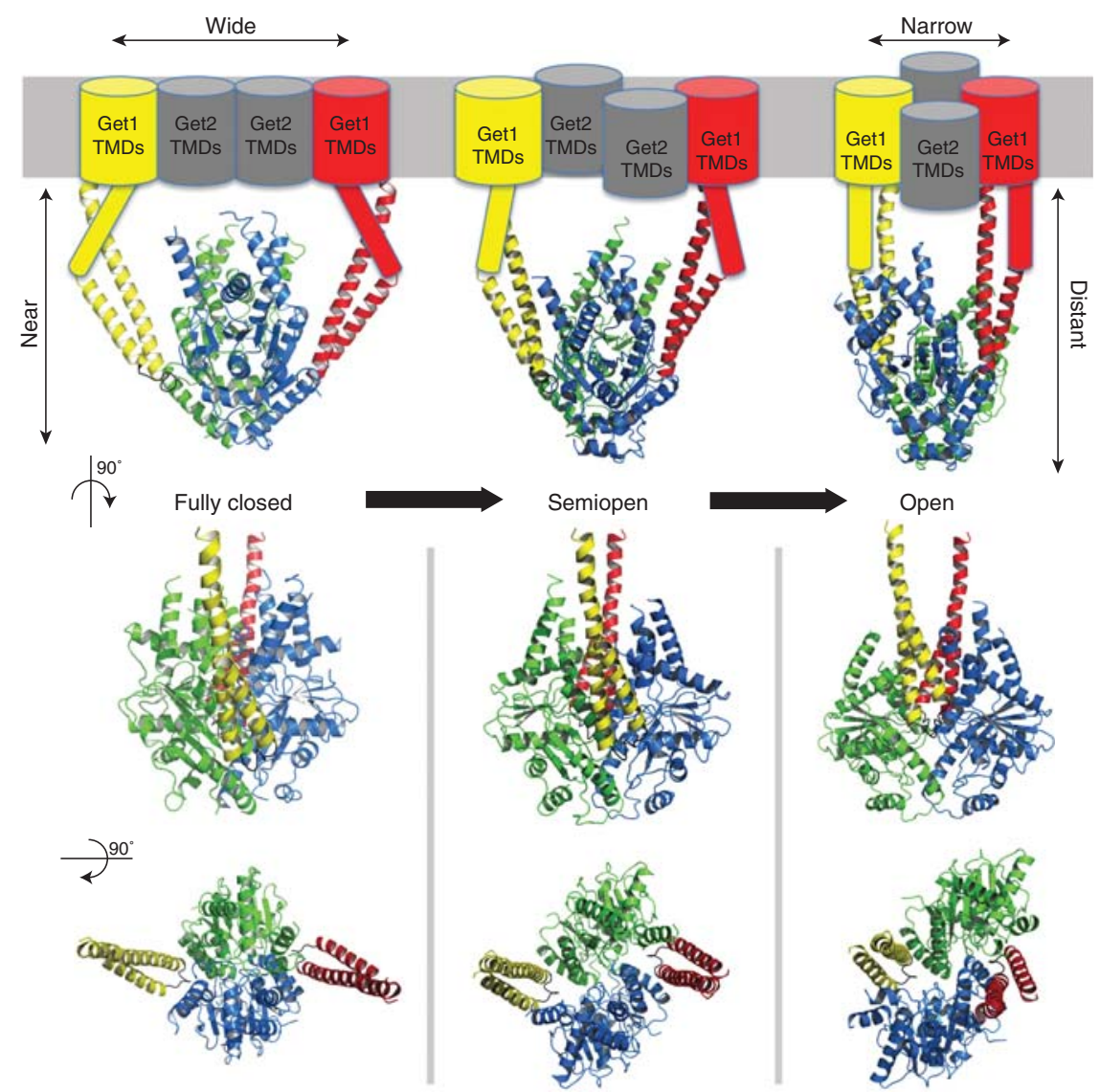

Figure 4. Hypothetical structural model for the insertion step of the GET pathway. Get 1 coiled coils might enable coupling between the opening of the Get3 dimer and movement of the transmembrane domains (TMDs). The predocking complex (left) is a hypothetical model of the Get3-Get1 interaction based on the fully closed Get3 state (2WOJ). Get1 docking causes the opening of the Get3 dimer via a semiopen state. Also shown are the associated hypothetical movements of Get3 relative to the membrane (from near to distant), as well as the coupled conformational changes in the Get1/2 TMDs (from wide to narrow).

example, does the release of substrate and hydrolyzed nucleotide from Get3 generate a "power stroke" that enables Get1/2 transmembrane domains to catalyze the insertion step? Furthermore, detailed biophysical and modeling studies will also be needed to turn the structural snapshots of the Get3 ATPase cycle into a movie of TA protein insertion. Together with characterization of conserved pathway components in higher eukaryotes and archaea, studies of the yeast GET pathway are well on their way to adding another textbook example of how cells chaperone membrane proteins into lipid bilayers.

\section{ACKNOWLEDGMENTS}

The authors thank Yin-Yuin Pang and Gert Bange for discussion, comments on the manuscript, and preparing the figures. I.S. acknowledges support by the DFG (SFB 638). V. Dötsch acknowledges support by the Deutsche Forschungsgemeinschaft (Do545/9), the Centre for Biomolecular Magnetic Resonance (BMRZ), and the Cluster of Excellence Frankfurt (Macromolecular Complexes). V.D. acknowledges support by the National Institutes of Health (RO1GM0999943-01), the 
V. Denic et al.

Ellison Medical Foundation, and Harvard University.

\section{REFERENCES}

Bozkurt G, Stjepanovic G, Vilardi F, Amlacher S, Wild K, Bange G, Favaloro V, Rippe K, Hurt E, Dobberstein B, et al. 2009. Structural insights into tail-anchored protein binding and membrane insertion by Get3. Proc Natl Acad Sci 106: 21131-21136.

Bozkurt G, Wild K, Amlacher S, Hurt E, Dobberstein B, Sinning I. 2010. The structure of Get4 reveals an $\alpha$ solenoid fold adapted for multiple interactions in tail-anchored protein biogenesis. FEBS Lett 584: 15091514.

Chang YW, Chuang YC, Ho YC, Cheng MY, Sun YJ, Hsiao CD, Wang C. 2010. Crystal structure of Get4Get5 complex and its interactions with Sgt2, Get3, and Ydj1. J Biol Chem 285: 9962-9970.

Chartron JW, Suloway CJ, Zaslaver M, Clemons WM Jr. 2010. Structural characterization of the Get $4 /$ Get 5 complex and its interaction with Get3. Proc Natl Acad Sci 107: 12127-12132.

Chartron JW, Gonzalez GM, Clemons WM Jr. 2011. A structural model of the Sgt 2 protein and its interactions with chaperones and the Get4/Get5 complex. J Biol Chem $\mathbf{2 8 6}$ 34325-34334.

Chartron JW, Clemons WM Jr, Suloway CJ. 2012a. The complex process of GETting tail-anchored membrane proteins to the ER. Curr Opin Struct Biol 22: 217-224.

Chartron JW, Vandervelde DG, Rao M, Clemons WM Jr. 2012b. The Get5 carboxyl terminal domain is a novel dimerization motif that tethers an extended Get4/Get5 complex. J Biol Chem 287: 8310-8317.

Dawson RJ, Locher KP. 2007. Structure of the multidrug $\mathrm{ABC}$ transporter Sav1866 from Staphylococcus aureus in complex with AMP-PNP. FEBS Lett 581: 935-938.

Denic V. 2012. A portrait of the GET pathway as a surprisingly complicated young man. Trends Biochem Sci 37: 411-417.

Grudnik P, Bange G, Sinning I. 2009. Protein targeting by the signal recognition particle. Biol Chem 390: 775782.

Hainzl T, Huang S, Merilainen G, Brannstrom K, SauerEriksson AE. 2011. Structural basis of signal-sequence recognition by the signal recognition particle. Nat Struct Mol Biol 18: 389-391.

Hegde RS, Keenan RJ. 2011. Tail-anchored membrane protein insertion into the endoplasmic reticulum. Nat Rev Mol Cell Biol 12: 787-798.

Hessa T, Sharma A, Mariappan M, Eshleman HD, Gutierrez E, Hegde RS. 2011. Protein targeting and degradation are coupled for elimination of mislocalized proteins. Nature 475: 394-397.

Hu J, Li J, Qian X, Denic V, Sha B. 2009. The crystal structures of yeast Get3 suggest a mechanism for tail-anchored protein membrane insertion. Plos ONE 4: e8061-e8061.

Janda CY, Li J, Oubridge C, Hernandez H, Robinson CV, Nagai K. 2010. Recognition of a signal peptide by the signal recognition particle. Nature 465: 507-510.
Keenan RJ, Freymann DM, Walter P, Stroud RM. 1998. Crystal structure of the signal sequence binding subunit of the signal recognition particle. Cell 94: 181-191.

Kohl C, Tessarz P, von der Malsburg K, Zahn R, Bukau B, Mogk A. 2011. Cooperative and independent activities of Sgt 2 and Get5 in the targeting of tail-anchored proteins. Biol Chem 392: 601-608.

Kubota K, Yamagata A, Sato Y, Goto-Ito S, Fukai S. 2012. Get1 stabilizes an open dimer conformation of get3 ATPase by binding two distinct interfaces. $J \mathrm{Mol} \mathrm{Biol}$ 422: $366-375$.

Leipe DD, Wolf YI, Koonin EV, Aravind L. 2002. Classification and evolution of P-loop GTPases and related ATPases. J Mol Biol 317: 41-72.

Liou ST, Wang C. 2005. Small glutamine-rich tetratricopeptide repeat-containing protein is composed of three structural units with distinct functions. Arch Biochem Biophys 435: 253-263.

Mariappan M, Mateja A, Dobosz M, Bove E, Hegde RS, Keenan RJ. 2011. The mechanism of membrane-associated steps in tail-anchored protein insertion. Nature 477: 61-66.

Mateja A, Szlachcic A, Downing ME, Dobosz M, Mariappan M, Hegde RS, Keenan RJ. 2009. The structural basis of tail-anchored membrane protein recognition by Get3. Nature 461: 361-366.

Rapoport TA. 2007. Protein translocation across the eukaryotic endoplasmic reticulum and bacterial plasma membranes. Nature 450: 663-669.

Rosendal KR, Wild K, Montoya G, Sinning I. 2003. Crystal structure of the complete core of archaeal signal recognition particle and implications for interdomain communication. Proc Natl Acad Sci 100: 14701-14706.

Schuldiner M, Metz J, Schmid V, Denic V, Rakwalska M, Schmitt HD, Schwappach B, Weissman JS. 2008. The GET complex mediates insertion of tail-anchored proteins into the ER membrane. Cell 134: 634-645.

Shao S, Hegde RS. 2011. Membrane protein insertion at the endoplasmic reticulum. Annu Rev Cell Dev Biol 27: $25-56$.

Sherrill J, Mariappan M, Dominik P, Hegde RS, Keenan RJ. 2011. A conserved archaeal pathway for tail-anchored membrane protein insertion. Traffic 12: 1119.

Simpson PJ, Schwappach B, Dohlman HG, Isaacson RL. 2010. Structures of Get3, Get4, and Get5 provide new models for TA membrane protein targeting. Structure 18: 897-902.

Stefanovic S, Hegde RS. 2007. Identification of a targeting factor for posttranslational membrane protein insertion into the ER. Cell 128: 1147-1159.

Stefer S, Reitz S, Wang F, Wild K, Pang YY, Schwarz D, Bomke J, Hein C, Lohr F, Bernhard F, et al. 2011. Structural basis for tail-anchored membrane protein biogenesis by the Get3-receptor complex. Science 333: 758-762.

Suloway CJ, Chartron JW, Zaslaver M, Clemons WM. 2009. Model for eukaryotic tail-anchored protein binding based on the structure of Get3. Proc Natl Acad Sci 106: 14849-14854.

Suloway CJ, Rome ME, Clemons WM Jr. 2012. Tail-anchor targeting by a Get 3 tetramer: The structure of an archaeal homologue. EMBO J 31: 707-719. 
The GET Pathway

Wang F, Brown EC, Mak G, Zhuang J, Denic V. 2010. A chaperone cascade sorts proteins for posttranslational membrane insertion into the endoplasmic reticulum. Mol Cell 40: 159-171.

Wang F, Whynot A, Tung M, Denic V. 2011. The mechanism of tail-anchored protein insertion into the ER membrane. Mol Cell 43: 738-750.
Wereszczynski J, McCammon JA. 2012. Nucleotide-dependent mechanism of Get3 as elucidated from free energy calculations. Proc Natl Acad Sci 109: 7759-7764.

Yamagata A, Mimura H, Sato Y, Yamashita M, Yoshikawa A, Fukai S. 2010. Structural insight into the membrane insertion of tail-anchored proteins by Get3. Genes Cells 15: $29-41$. 


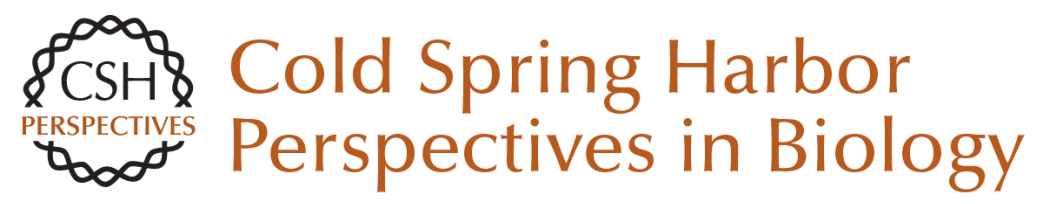

\section{Endoplasmic Reticulum Targeting and Insertion of Tail-Anchored Membrane Proteins by the GET Pathway}

Vladimir Denic, Volker Dötsch and Irmgard Sinning

Cold Spring Harb Perspect Biol 2013; doi: 10.1101/cshperspect.a013334

Subject Collection The Endoplasmic Reticulum

Sorting and Export of Proteins at the Endoplasmic

Reticulum Ishier Raote, Sonashree Saxena and Vivek Malhotra

Endoplasmic Reticulum Membrane Contact Sites, Lipid Transport, and Neurodegeneration Andrés Guillén-Samander and Pietro De Camilli

AMPylation and Endoplasmic Reticulum Protein Folding Homeostasis Luke A. Perera and David Ron

The Endoplasmic Reticulum and the Fidelity of Nascent Protein Localization

Michael J. McKenna and Sichen Shao

Endoplasmic Reticulum Architecture and Inter-Organelle Communication in Metabolic Health and Disease

Ana Paula Arruda and Günes Parlakgül

Regulation and Functions of the ER-Associated Nrf1 Transcription Factor

Gary Ruvkun and Nicolas Lehrbach

Mechanism of Protein Translocation by the Sec61 Translocon Complex

Samuel Itskanov and Eunyong Park
Glycerolipid Synthesis and Lipid Droplet

Formation in the Endoplasmic Reticulum Robert V. Farese, Jr. and Tobias C. Walther

The Biogenesis of Multipass Membrane Proteins Luka Smalinskaite and Ramanujan S. Hegde

A TAle of Two Pathways: Tail-Anchored Protein Insertion at the Endoplasmic Reticulum Alina Guna, Masami Hazu, Giovani Pinton Tomaleri, et al.

Cholesterol Transport to the Endoplasmic Reticulum John P. Kennelly and Peter Tontonoz

The Role of the Rhomboid Superfamily in ER Protein Quality Control: From Mechanisms and Functions to Diseases

Satarupa Bhaduri, Nicola A. Scott and Sonya E. Neal

ER-Phagy: Quality and Quantity Control of the

Endoplasmic Reticulum by Autophagy Haruka Chino and Noboru Mizushima

Structure and Function of the Nuclear Pore

Complex

Stefan Petrovic, George W. Mobbs, Christopher J. Bley, et al.

For additional articles in this collection, see http://cshperspectives.cshlp.org/cgi/collection/

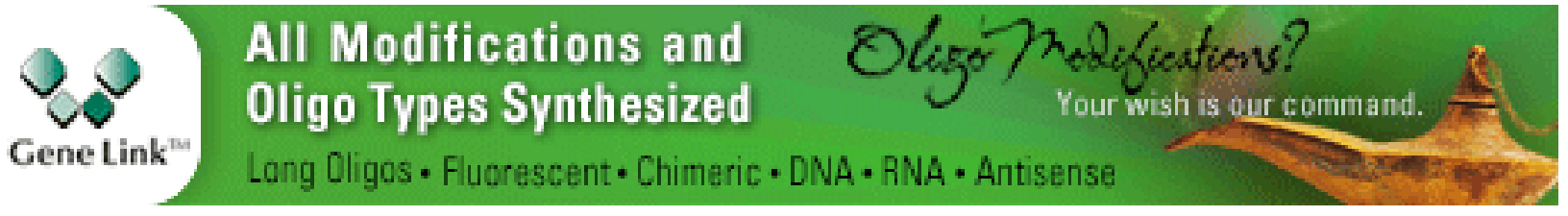




\section{Evolutionary Aspects of the Unfolded Protein Response \\ Kazutoshi Mori}

Post-Translational Regulation of HMG CoA Reductase

Youngah Jo and Russell A. DeBose-Boyd

For additional articles in this collection, see http://cshperspectives.cshlp.org/cgi/collection/

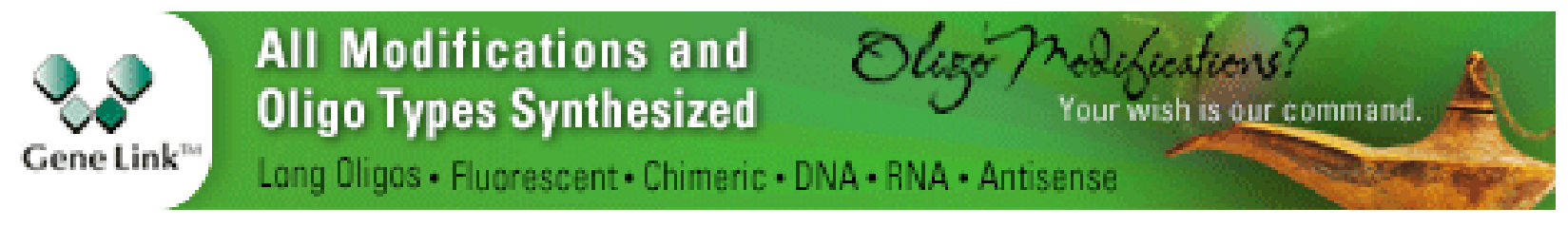

Copyright @ 2013 Cold Spring Harbor Laboratory Press; all rights reserved 